\title{
Music for Pain Control Following Orthodontic Initial Archwire Placement
}

\author{
MUHAMMAD AZEEM ${ }^{1}$, ZAINAB EJAZ ${ }^{2}$, AYESHA ASHRAF $^{3}$, FAREEHA BUKHARI $^{4}$, MUNAWAR MANZOOR ALI $^{5}$, ABDUL $^{2}$ \\ RASHID 6 \\ ${ }^{1}$ Assistant Professor Orthodontics, de'Montmorency College of Dentistry, Lahore, Pakistan. \\ ${ }^{2}$ PGR Orthodontics, de'Montmorency College of Dentistry, Lahore, Pakistan. \\ ${ }^{3}$ Assistant Professor Orthodontics, $\mathrm{CH} / \mathrm{ICH}$, Lahore, Pakistan. \\ ${ }^{4}$ Associate Professor Orthodontics, UOL/UMDC, Lahore, Pakistan. \\ ${ }^{5}$ Assistant Professor Orthodontics, UOL/UMDC, Lahore, Pakistan. \\ ${ }^{6}$ Associate Professor/HOD/Classified Specialist Oral \& Maxillofacial Surgery, Fauji Foundation, Lahore, Pakistan. \\ Correspondence to Dr Muhammad Azeem, dental.concepts@hotmail.com
}

\begin{abstract}
Background: Pain control is very important aspect of orthodontic practice.

Aim: To compare the efficacy of music therapy for pain control following initial archwire placement in orthodontics. Methods: This randomized control trial was conducted at orthodontics department. The study consisted of 50 orthodontic subjects from 1.1.2019 to 1.30.2020. Purposive sampling technique was used. 25 were in control group while other 25 were randomly allocated to music group. The pain was recorded using VAS scale at multiple points of time following archwire placement. T-test was used for the statistical analysis.

Results: The study found that there was insignificant difference in mean pain scores between the two groups with less pain scores in music group.

Conclusion: Music can play an effective role in pain control following orthodontic initial bonding.

Keywords: Music; Orthodontics.
\end{abstract}

\section{INTRODUCTION}

Music therapy for pain control in dentistry is not a new method. ${ }^{1-3}$ Music therapy is used in dentistry for pain control following many dental procedures with successful outcomes. ${ }^{4-6}$ The main advantage of music in pain control is avoidance of drugs and its associated side effects. ${ }^{7-8}$

Pain following orthodontic therapy is one of the most common reasons of avoidance of orthodontic therapy ${ }^{9}$ There are various traditional methods of pain control following orthodontic initial arch wire placement such as pharmaceutical agents. ${ }^{10-12}$ There are also various latest ways of pain control following initial orthodontic arch wire placement such as chewing gums, lasers, vibrations, ultrasonic rays, and low level laser therapy. ${ }^{13-15}$

Music can actually calm patients, improve vital signs and enhance patient's overall well being. ${ }^{16}$ Music act as an audio analgesia for relieving pain and anxiety by moving conscious thought away.

Therefore; aim of this study is to compare the efficacy of music therapy for pain control following initial arch wire placement in orthodontics.

\section{MATERIAL AND METHODS}

The objective of this study was to compare the efficacy of music therapy for pain control following initial archwire placement in orthodontics. This randomized control trial was conducted at orthodontics department. The study consisted of 50 orthodontic subjects from 1.1.2019 to 1.30.2020. Purposive sampling technique was used. 25 were in control group while other 25 were randomly allocated to music group. The pain was recorded using

Received on 13-02-2021

Accepted on 23-05-2021
VAS scale at multiple points of time following archwire placement. Following was the selection criteria: Orthodontic patients of both genders, age 12-16 years, mild to moderate crowding, candidate of fixed appliance therapy by non-extraction plan, no history of orthodontic treatment, willing to take part in study, patients with insignificant medical and drug history.

Descriptive statistics were computed. Frequency and percentage has been reported for the categorical variable such as gender. Mean and standard deviation (SD) has been reported for the quantitative variable such as age and pain scores. t-test was used for the statistical analysis between the two groups.

\section{RESULTS}

The study found that there was insignificant difference in mean pain scores between the two groups with less pain scores in music group (Table 1).

Table 1: Pain scores in the two groups.

\begin{tabular}{|l|c|c|c|}
\hline Time point & Control group $^{*}$ & Music group $^{*}$ & P-value \\
\hline Baseline & $0.32 \pm 1.12$ & $0.37 \pm 1.01$ & 0.456 \\
\hline Immediately & $3.23 \pm 1.12$ & $1.16 \pm 1.23$ & 0.213 \\
\hline 12 hours & $6.72 \pm 1.65$ & $5.33 \pm 1.67$ & 0.345 \\
\hline 24 hours & $7.89 \pm 1.22$ & $6.23 \pm 1.43$ & 0.267 \\
\hline 3 days & $2.34 \pm 1.43$ & $1.78 \pm 1.88$ & 0.211 \\
\hline 7 days & $0.22 \pm 1.94$ & $0.10 \pm 1.90$ & 0.345 \\
\hline
\end{tabular}

${ }^{*}$ t test

\section{DISCUSSION}

Music therapy is used in dentistry for pain control following many dental procedures with successful outcomes. ${ }^{4-6}$ The main advantage of music in pain control is avoidance of drugs and its associated side effects. ${ }^{7-8}$ The aim of this 
study was to compare the efficacy of music therapy for pain control following initial archwire placement in orthodontics. Pain following orthodontic therapy is one of the most common reasons of avoidance of orthodontic therapy ${ }^{9}$ There are various traditional methods of pain control following orthodontic initial arch wire placement such as pharmaceutical agents. ${ }^{10-12}$ There are also various latest ways of pain control following initial orthodontic arch wire placement such as chewing gums, lasers, vibrations, ultrasonic rays, and low level laser therapy. ${ }^{13-15}$

The result of the present study showed that there was insignificant difference in mean pain scores between the two groups with less pain scores in music group. The less pain scores in music group can be linked to the fact that music can actually calm patients, improve vital signs and enhance patient's overall well being. ${ }^{16}$ Music act as an audio analgesia for relieving pain and anxiety by moving conscious thought away. ${ }^{16}$

The results are somehow in agreement with the findings of other studies by Xu et al, Huang et al and Zheng et al which showed that music therapy was effective for control of pain following initial archwire activation possibly via restoring functional connectivity and brain regularity influenced by pain. ${ }^{14-16}$

There are certain limitations of the present study such as small sample size and single centric study. However within these limitations the result of present study showed that there was insignificant difference in mean pain scores between the two groups with less pain scores in music group.

\section{CONCLUSION}

Music can play an effective role in pain control following orthodontic initial bonding. Further large-scale studies are suggested.

\section{Conflict of interest: Nil}

\section{REFERENCES}

1. Bradt J, Teague A. Music interventions for dental anxiety. Oral diseases. 2018 Apr;24(3):300-6.

2. Standley J. Music as a therapeutic intervention in medical and dental treatment: Research and clinical applications. The art and science of music therapy: A handbook. 1995:3-22.

3. Ainscough SL, Windsor L, Tahmassebi JF. A review of the effect of music on dental anxiety in children. European Archives of Paediatric Dentistry. 2019 Feb;20(1):23-6.
4. Vazirani N, Samani J, Faran T, Allohaibi Z, Mantesso A, Karl $\mathrm{E}$. The use of a series of string quartet live music concert to reduce anxiety in first-year dental students. International Journal of Applied Dental Sciences. 2020;6(1):236-9.

5. Ghasemi M, Lotfollahzadeh $H$, Kermani-Ranjbar $T$, Kharazifard MJ. Effect of music practice on anxiety and depression of Iranian dental students. Journal of Dentistry (Tehran, Iran). 2017 May;14(3):138.

6. MEHARWADE P, CHINDAK S, KAJJARI S, UPPIN C, HUGAR SM, BADAKAR C. Effect of Music Distraction in Managing Anxious Paediatric Dental Patients-A Review. Journal of Clinical \& Diagnostic Research. 2021 Feb 1;15(2).

7. Mahsa K. The effect of using non-verbal music on the pain and anxiety of impacted wisdom tooth surgery (Doctoral dissertation, Mazandaran university of medical sciences).

8. Pintea S, Gatlan D, Kállay É, Jucan A. The effect of symphonic and lounge music upon anxiety and pain in a sample of Romanian dental patients. Cognitie, Creier, Comportament/Cognition, Brain, Behavior. 2017 Jun 1;21(2).

9. Azeem M, Khan DI, Jamal F, Ali S, Fatima M, Hayat MB, Shakoor MU. Chewing gum for pain control following orthodontic separator placement. Journal of the World Federation of Orthodontists. 2018 Sep 1;7(3):102-5.

10. Figueira IZ, Sousa AC, Machado AW, Habib FA, Soares LG, Pinheiro AL. Clinical study on the efficacy of LED phototherapy for pain control in an orthodontic procedure. Lasers in medical science. 2019 Apr;34(3):479-85.

11. Eslamipour F, Motamedian SR, Bagheri F. Ibuprofen and Low-level Laser Therapy for Pain Control during Fixed Orthodontic Therapy: A Systematic Review of Randomized Controlled Trials and Meta-analysis. The journal of contemporary dental practice. 2017 Jun 1;18(6):527-33.

12. Correa AS, ALMEIDA VL, Lopes B, Franco A, MATOS FR, Quintans-Junior LJ, Rode SM, Paranhos LR. The influence of non-steroidal anti-inflammatory drugs and paracetamol used for pain control of orthodontic tooth movement: a systematic review. Anais da Academia Brasileira de Ciências. 2017 Dec;89(4):2851-63.

13. Mirhashemi A, Rasooli R, Shahi S, Chiniforush N. Efficacy of Photobiomodulation Therapy for Orthodontic Pain Control Following the Placement of Elastomeric Separators: A Randomized Clinical Trial. Journal of Lasers in Medical Sciences. 2021;12:e8-.

14. Xiaomei X, Lihua Z, Yahua J, Yue H, Suhua H, Siwei $Y$. Clinical research of music in relieving orthodontic pain. West China Journal of Stomatology. 2013 Aug 1;31(4).

15. NUMATA K. Effects of Sound Masking on the Treatment in Dental Orthodontics. The Journal of Nihon University School of Dentistry. 1964;6(3):105-10.

16. Huang $R$, Wang J, Wu D, Long $H$, Yang X, Liu H, Gao X, Zhao R, Lai W. The effects of customised brainwave music on orofacial pain induced by orthodontic tooth movement. Oral diseases. 2016 Nov;22(8):766-74. 